\title{
Epstein-Barr virus infection and chronic lymphocytic leukemia: a possible progression factor?
}

\author{
Riccardo Dolcetti ${ }^{*}$, Antonino Carbone $^{2}$
}

\begin{abstract}
Epstein-Barr virus is pathogenically associated with a well defined group of lymphoid and epithelial tumors in which the virus directly drives transformation of infected cells. Recent evidence however indicates that this virus may infect a subpopulation of tumor cells in patients with chronic lymphocytic leukemia (CLL) and EBV infection has been also associated with Richter transformation in a fraction of cases. We herein review available data suggesting a possible role of EBV as a direct or micro-environmental progression factor in a subset of CLL.
\end{abstract}

\section{Introduction}

The Epstein-Barr virus (EBV) was first identified 40 years ago in cultured Burkitt's lymphoma cells when no human lymphoid cell had ever been maintained in culture [1]. EBV has a world-wide distribution being able to establish a lifelong infection in more than $90 \%$ of individuals. Primary infection is usually asymptomatic and only when it is delayed until adolescence or adulthood a benign lymphoproliferative disease, known as infectious mononucleosis (IM), may occur. The main site of EBV persistence in vivo is represented by latently infected B cells showing features of resting memory B lymphocytes $[2,3]$. Under normal circumstances, EBV is able to establish a persistent infection in vivo without affecting the behavior of B lymphocytes. To do so, the virus has evolved an elegant strategy based on the subtle exploitation of virtually all aspects of B cell physiology. The final outcome of the interaction between EBV and the infected host is the establishment of a nonpathogenic latent infection of memory $B$ lymphocytes that allows the virus to persist for the lifetime. Evidence accumulated so far, in particular the presence of EBV genomes and the constant expression of viral proteins, strongly support the involvement of EBV in the pathogenesis of a wide spectrum of human malignancies. These include lymphomas of $\mathrm{B}, \mathrm{T}$ and NK cell origin

\footnotetext{
*Correspondence: rdolcetti@cro.it

${ }^{1}$ Cancer Bio-Immunotherapy Unit, CRO - IRCCS, National Cancer Institute, Via Franco Gallini 2, 33081 Aviano, Italy

Full list of author information is available at the end of the article
}

such as the immunoblastic lymphoma of immunosuppressed, endemic Burkitt's lymphoma (BL), Hodgkin's Lymphoma (HL), and some T/NK cell lymphoma, but also carcinomas of the nasopharynx and stomach and leiomyosarcomas arising in organ transplant patients and HIV-infected individuals [4]. EBV-induced immortalization/transformation is mediated by the activity of viral proteins that interfere with crucial cellular pathways controlling growth and/or survival. These viral proteins act cooperatively and may induce different biologic effects in different cellular backgrounds [4]. On the basis of the different pattern of latent EBV genes expressed in EBV-associated tumors, three main types of virus latency have been identified. Latency I is the more restricted form of viral gene expression and characterizes BL, which expresses only the EBV nuclear antigen (EBNA)-1 and the EBV RNAs (EBERs). In contrast, latency III involves the unrestricted expression of all the 6 EBNAs together with the latent membrane proteins (LMP)-1 and LMP-2. This type of latency mainly occurs in the setting of severe immune suppression and characterizes post-transplant and HIV-associated lymphoproliferative disorders, and is usually observed in EBVimmortalized lymphoblastoid cell lines in vitro. Latency II is an intermediate form of virus latency in which, besides EBNA-1 and EBERs, only LMP-1 and -2 are expressed. This pattern of EBV gene expression is observed in HL, T/NK cell lymphoma, and nasopharyngeal carcinoma (NPC). 
EBV can be considered as the prototype of oncogenic viruses that behave as direct transforming agents. In fact, in classical EBV-associated tumors, the virus genome is present in virtually all neoplastic cells, which show the expression of viral RNAs and proteins that variously contribute to the induction of the transformed phenotype. On the basis of these features and of the strict association with distinct tumor types, EBV has been classified as a group I carcinogen. An additional compelling factor is the presence of homogeneous (clonal) EBV episomes detected with the use of the virus termini assay in several EBV-related tumors (HL, NPC, $\mathrm{BL}$ ) as well as in some pre-neoplastic lesions. These findings suggest that these tumors develop from a single cell that was infected by EBV before the outgrowth and are consistent with a role for EBV in the early phases of tumor development.

Besides the well defined group of tumors pathogenically associated with EBV according to the criteria mentioned above, the presence of this herpesvirus has been variably detected in a broad spectrum of other tumors for which a causal role of EBV seems unlikely. These tumors include also chronic lymphocytic leukemia. We herein briefly review available data suggesting a possible role of EBV as a direct or microenvironmental progression factor in a fraction of CLL.

\section{Chronic lymphocytic leukemia and Richter's syndrome}

Chronic lymphocytic leukemia (CLL) is the most common type of adult leukemia in the United States and Western Europe. CLL cells are small lymphoid B cells with scant cytoplasm having a regular outline. Nuclei contain clumped chromatin and nucleoli are usually absent. On bone marrow and peripheral blood smears the CLL variant with increased prolymphocytes (CLL/ PLL), consists of more than $10 \%$, but less than $55 \%$ prolymphocytes. Bone marrow histologic pattern may be nodular, interstitial, diffuse, or a combination of the three. These patterns correlate with prognosis [5]. CLL cells express surface IgM or IgM and IgD, CD5, CD19, and CD23. Ig genes are rearranged. $40-50 \%$ of cases are un-mutated and 50-60\% show somatic hypermutations. There is a group of genes that distinguishes the two genetic subytpes. ZAP-70 is among the genes whose expression is associated with an IgHV un-mutated CLL genotype [5]. About 50\% of CLL show 13q deletion, about $20 \%$ trisomy 12 and, less commonly, other genomic abnormalities. Low stage patients with mutated CLL have a better prognosis than those with un-mutated CLL. ZAP-70 and CD38 expression of are associated with a poor prognosis [5].

A small fraction (approximately 2-8\%) of patients with CLL develop diffuse large B-cell lymphoma (DLBCL).
This event has been termed Richter's syndrome or Richter's transformation [6] and is associated with poor response to treatment and low survival times [5]. Richter's syndrome is histologically characterized by confluent sheets of large cells that may resemble centroblastor immunoblast-like cells. The majority of the reported DLBCL occurring in patients with CLL are clonally related to the previous CLL $[7,8]$. An interesting finding is the occurrence of scattered Hodgkin and Reed Sternberg (HRS)-like cells in the background. In contrast to true Hodgkin lymphoma arising in CLL patients, the reactive typical background is absent and the HRS-like cells are surrounded by neoplastic B-cells. These HRSlike cells show evidence of EBV infection (Figure 1).

\section{EBV and chronic lymphocytic leukemia}

EBV infection is only infrequently detected in CLL by conventional diagnostic approaches. This is consistent with in vitro findings indicating that CLL cells do not regularly become activated or immortalized after exposure to EBV [9], although this can be achieved following cytokine activation [10]. It has been shown, in particular, that the combined treatment with Staphylococcus aureus Cowan I (SAC), MP6-thioredoxin, and interleukin 2 can render CLL cells susceptible to EBV infection in vitro [10]. Therefore, although basally refractory, CLL cells may become occasionally infected by EBV in vivo provided that mitogenic and activating signals are available within the microenvironment. In CLL cells, however, the expression of the EBV-encoded nuclear proteins EBNAs is not followed by entrance into the cell cycle. In fact, unlike what observed in normal B lymphocytes, EBV-infected CLL cells remain resting and do not express c-myc, cyclin D2, or pRb, whereas the p27 cell cycle inhibitor is not down-regulated [11].

In CLL cases showing EBV infection, EBV markers are however detectable only in a subpopulation of tumor cells $[12,13]$. Notably, several studies have reported that expression of EBERs detected by in situ hybridization correlated with progressive or accelerated clinical courses [13-16]. EBERs are small non-coding RNAs abundantly expressed in latently infected cells that play critical role in B cell transformation and induction of resistance to apoptosis [17], and may therefore directly contribute to CLL progression. Further characterization of EBV infection in this setting allowed the demonstration of LMP-1 mRNA expression in isolated CLL cells but not in normal resting B lymphocytes [18]. More recently, LMP-1 transcriptional activity was detected in a significant proportion of CLL cases $(14 \% v s .1 \%$ of healthy controls) [19]. Notably, CLL patients showing LMP-1 mRNA expression had a higher extent of marrow involvement [19]. Although a confirmation that LMP-1 is expressed also at the protein level is still 


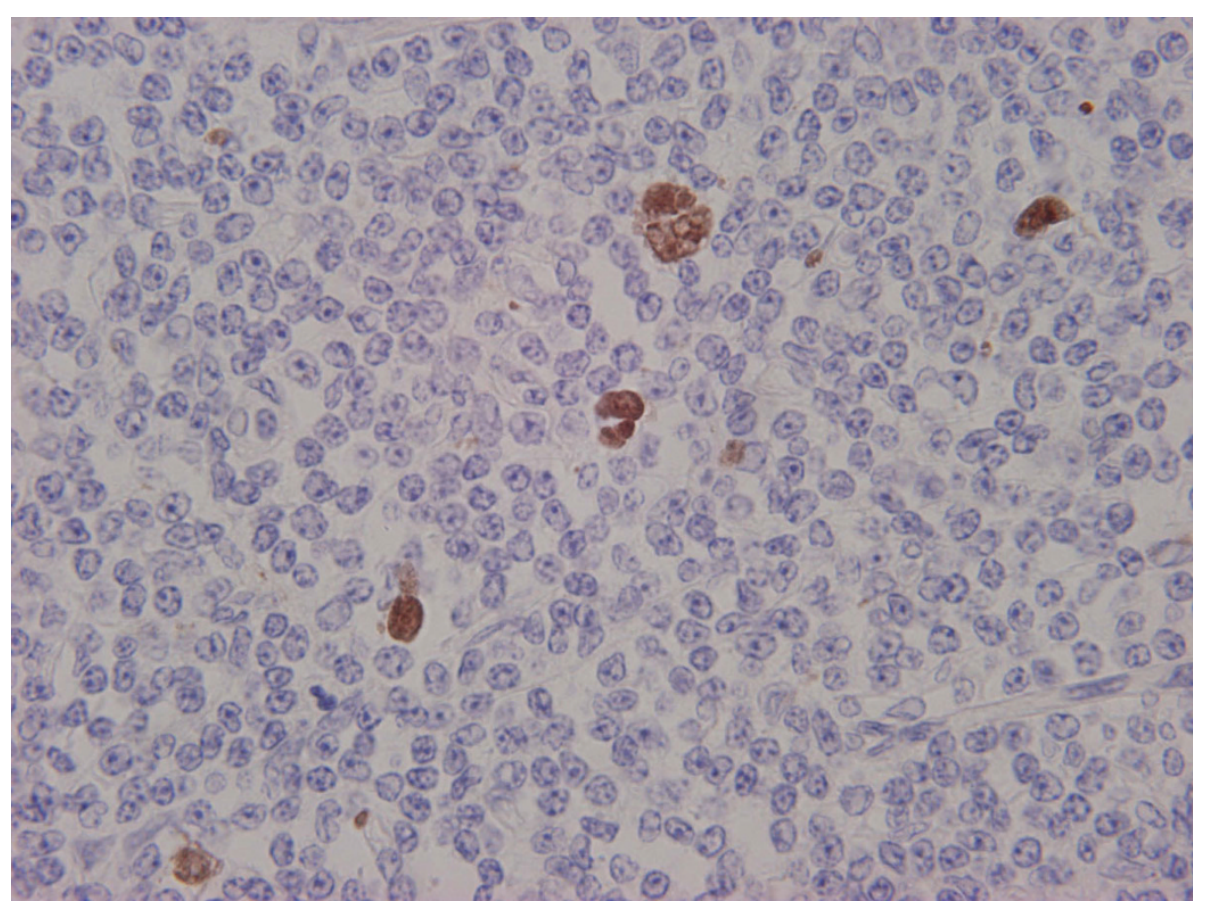

Figure 1 Richter's transformation of a CLL case. In situ EBER hybridization shows nuclear staining in giant Hodgkin/Reed-Sternberg-like cells $(660 \times)$

lacking, available evidence is consistent with a possible role for EBV in the malignant progression of the disease. EBV infection has been also associated with a fraction of CLL transformation to diffuse large cell lymphoma or Richter syndrome, particularly in cases displaying a high number of Reed-Sternberg-like cells [15,20-23]. Cases of CLL transformation to HL have been also reported $[23,24]$. Considering that LMP-1 drives the morphologic and transcriptional changes characteristic of Hodgkin/ Reed-Sternberg cells [25], the detection of LMP-1 expression in tumor cells of a fraction of CLL cases is particularly intriguing and deserves further investigation. In some, but not all cases, the malignant transformation involves cells originating from the CLL clone, as shown by immunoglobulin gene rearrangement studies [26-29], further supporting the role of secondary EBV infection as a possible cyto-morphologic and clinical progression factor for CLL. In clonally distinct cases, the immune suppression induced by drugs such as fludarabine or anti-CD52 antibodies may favor the outgrowth of an unrelated, EBV-infected B cell clone that may lead to a clinically aggressive disease resembling EBV-associated lymphoproliferations of immunosuppressed patients. These cases should be distinguished from Richter syndrome, probably representing a novel type of immunodeficiency-related lymphoma.

Besides behaving as a direct drive of neoplastic progression in EBV-infected CLL cells, the presence of EBV within tumor microenvironment could also indirectly contribute to the malignant evolution of the disease. Indeed, EBV may infect a subpopulation of CLL cells and/or may be carried by bystander normal B lymphocytes. EBV infection and, particularly, LMP-1 expression, by CLL cells may promote angiogenesis by inducing IL-8 [30], and increasing the production of vascular endothelial growth factor [31]. Moreover, EBV may induce/enhance the production of cytokines, such as cellular IL-10 (cIL-10), able to promote B cell proliferation and inhibit $\mathrm{T}$ cell responses [32]. Notably, serum cIL-10 levels are increased in CLL patients and correlate with adverse disease features and short survival [33]. Intriguingly, assays measuring both EBV-derived (viral IL-10) and human cIL-10 yielded higher values than assays specifically quantifying human cIL-10 [33]. These findings indirectly indicate that, in a fraction of CLL cases, EBV infection is not silent, being associated with enhanced production of viral IL-10. EBV may also contribute to a local immune suppression through the production of hydrophobic peptides derived from the first transmembrane domain of LMP-1 [34]. These peptides, in fact, potently inhibit both cytotoxic $\mathrm{T}$ lymphocyte and natural killer cell responses in vitro [34].

\section{Concluding remarks and future perspectives}

In CLL, evidence for EBV infection was obtained only in a subset of cases and, notably, only in a variable fraction 
of neoplastic cells. These findings contrast with the constant presence of EBV genome in all tumor cells of malignancies pathogenically linked to the virus and argue against a causal role for EBV in the early phases of CLL development. Although a partial loss of viral genomes can not be formally excluded in these cases, this possibility appears however unlikely. Moreover, the fact that viral products necessary to sustain the transformed phenotype may be expressed only by a fraction of tumor cells further weakens the hypothesis of a pathogenic involvement of EBV in this tumor. Although further studies are required to elucidate this complex and still debated issue, available evidence briefly reviewed herein is consistent with a possible role of EBV infection as a secondary event occurring after cell transformation and affecting a subpopulation of CLL cells in which the virus may promote the evolution to a more malignant phenotype. The possible prognostic role of EBV-driven production of factors able to promote CLL cell growth, angiogenesis and to inhibit tumor-specific immune responses deserves to be carefully investigated by prospective studies. If such progression mechanisms will be conclusively demonstrated, the use of antagonists or inhibitors of molecules produced by EBV-infected cells could represent a potentially attractive therapeutic approach.

\section{Acknowledgements}

The study was supported in part by grants from the European Community (FP6 VITAL, Contract no.: 037874), the Italian Ministry of Health program "Alleanza Contro il Cancro (ACC-4)" and the Associazione Italiana per la Ricerca sul Cancro.

\section{Author details}

${ }^{1}$ Cancer Bio-Immunotherapy Unit, CRO - IRCCS, National Cancer Institute, Via Franco Gallini 2, 33081 Aviano, Italy. ${ }^{2}$ Pathology Unit, CRO - IRCCS, National Cancer Institute, Via Franco Gallini 2, 33081 Aviano, Italy.

\section{Authors' contributions}

$\mathrm{RD}$ and $\mathrm{AC}$ conceived and wrote the review manuscript. All authors read and approved the final manuscript.

\section{Competing interests}

The authors declare that they have no competing interests.

Received: 8 November 2010 Accepted: 22 November 2010 Published: 22 November 2010

\section{References}

1. Epstein MA, Achong BG, Barry YM: Virus particles in cultured lymphoblasts from Burkitt's lymphoma. Lancet 1964, 1(7335):702-703.

2. Miyashita EM, Yang B, Babcock GJ, Thorley-Lawson DA: Identification of the site of Epstein-Barr virus persistence in vivo as a resting $B$ cell. $J$ Virol 1997, 71(7):4882-4891.

3. Babcock GJ, Decker LL, Volk M, Thorley-Lawson DA: EBV persistence in memory B cells in vivo. Immunity 1998, 9(3):395-404.

4. Dolcetti R, Masucci MG: Epstein-Barr virus: induction and control of cell transformation. J Cell Physiol 2003, 196(2):207-218.

5. Swerdlow SH, Campo E, Harris NL, et al: WHO Classification of tumours of Haematopoietic and lymphoid tissues IARC Press, Lyon, France; 2008.

6. Richter MN: Generalized reticular cell sarcoma of lymph nodes associated with lymphatic leukemia. Am J Pathol: 1928, IV(4):285-292.
7. Timar B, Fulop Z, Csernus B, Angster C, Bognar A, Szepesi A, Kopper L, Matolcsy A: Relationship between the mutational status of $\mathrm{VH}$ genes and pathogenesis of diffuse large B-cell lymphoma in Richter's syndrome. Leukemia 2004, 18(2):326-330.

8. Mao Z, Quintanilla-Martinez L, Raffeld M, Richter M, Krugmann J, Burek C, Hartmann E, Rudiger T, Jaffe ES, Muller-Hermelink HK, Ott G, Fend F, Rosenwald A: IgVH mutational status and clonality analysis of Richter's transformation: diffuse large B-cell lymphoma and Hodgkin lymphoma in association with B-cell chronic lymphocytic leukemia (B-CLL) represent 2 different pathways of disease evolution. Am J Surg Pathol 2007, 31(10):1605-1614.

9. Teramoto N, Gogolak P, Nagy N, Maeda A, Kvarnung K, Bjorkholm T, Klein E: Epstein-Barr virus-infected B-chronic lymphocyte leukemia cells express the virally encoded nuclear proteins but they do not enter the cell cycle. J Hum Virol 2000, 3(3):125-136.

10. Wendel-Hansen V Sallstrom J, De Campos-Lima PO, Kjellstrom G Sandlund A, Siegbahn A, Carlsson M, Nilsson K, Rosen A: Epstein-Barr virus (EBV) can immortalize B-cll cells activated by cytokines. Leukemia 1994 8(3):476-484

11. Maeda A, Bandobashi K, Nagy N, Teramoto N, Gogolak P, Pokrovskaja K, Szekely L, Bjorkholm M, Klein G, Klein E: Epstein-barr virus can infect B-chronic lymphocytic leukemia cells but it does not orchestrate the cell cycle regulatory proteins. J Hum Virol 2001, 4(5):227-237.

12. Bueso-Ramos CE, Ferrajoli A, Medeiros LJ, Keating MJ, Estrov Z: Aberrant morphology, proliferation, and apoptosis of B-cell chronic lymphocytic leukemia cells. Hematology 2004, 9(4):279-286.

13. Tsimberidou AM, Keating MJ, Bueso-Ramos CE, Kurzrock R: Epstein-Barr virus in patients with chronic lymphocytic leukemia: a pilot study. Leuk Lymphoma 2006, 47(5):827-836.

14. Tsimberidou AM, O'Brien S, Kantarjian HM, Koller C, Hagemeister FB, Fayad L, Lerner S, Bueso-Ramos CE, Keating MJ: Hodgkin transformation of chronic lymphocytic leukemia: the M. D. Anderson Cancer Center experience. Cancer 2006, 107(6):1294-1302.

15. Ansell SM, Li CY, Lloyd RV, Phyliky RL: Epstein-Barr virus infection in Richter's transformation. Am J Hematol 1999, 60(2):99-104.

16. Lazzarino M, Orlandi E, Baldanti F, Furione M, Pagnucco G, Astori C, Arcaini L, Viglio A, Paulli M, Gerna G, Bernasconi C: The immunosuppression and potential for EBV reactivation of fludarabine combined with cyclophosphamide and dexamethasone in patients with lymphoproliferative disorders. Br J Haematol 1999, 107(4):877-882.

17. Iwakiri $D$, Takada K: Role of EBERs in the pathogenesis of EBV infection. Adv Cancer Res 2010, 107:119-136.

18. Laytragoon-Lewin N, Chen F, Avila-Carino J, Zou JZ, Mellstedt H, Ernberg I, Klein G: Epstein Barr virus (EBV)-carrying cells of a chronic lymphocytic leukemia (CLL) subpopulation express EBNA1 and LMPs but not EBNA2 in vivo. Int J Cancer 1995, 63(4):486-490

19. Tarrand JJ, Keating MJ, Tsimberidou AM, O'Brien S, LaSala RP, Han XY, Bueso-Ramos CE: Epstein-Barr virus latent membrane protein 1 mRNA is expressed in a significant proportion of patients with chronic lymphocytic leukemia. Cancer 2010, 116(4):880-887.

20. Tsang WY, Chan JK, Sing C: The nature of Reed-Sternberg-like cells in chronic lymphocytic leukemia. Am J Clin Pathol 1993, 99(3):317-323.

21. Momose H, Jaffe ES, Shin SS, Chen YY, Weiss LM: Chronic lymphocytic leukemia/small lymphocytic lymphoma with Reed-Sternberg-like cells and possible transformation to Hodgkin's disease. Mediation by EpsteinBarr virus. Am J Surg Pathol 1992, 16(9):859-867.

22. Tsang WY, Chan JK, Ng CS: Epstein-Barr virus and Reed-Sternberg-like cells in chronic lymphocytic leukemia. Am J Surg Pathol 1993, 17(8):853-854

23. Petrella T, Yaziji N, Collin F, Rifle G, Morlevat F, Arnould L, Fargeot P, Depret O: Implication of the Epstein-Barr virus in the progression of chronic lymphocytic leukaemia/small lymphocytic lymphoma to Hodgkin-like lymphomas. Anticancer Res 1997, 17(5B):3907-3913.

24. Fayad L, Robertson LE, O'Brien S, Manning JT, Wright S, Hagemeister F, Cabanillas F, Keating MJ: Hodgkin's disease variant of Richter's syndrome: experience at a single institution. Leuk Lymphoma 1996, 23(3-4):333-337.

25. Vockerodt M, Morgan SL, Kuo M, Wei W, Chukwuma MB, Arrand JR, Kube D, Gordon J, Young LS, Woodman CB, Murray PG: The Epstein-Barr virus oncoprotein, latent membrane protein-1, reprograms germinal centre $B$ cells towards a Hodgkin's Reed-Sternberg-like phenotype. J Pathol 2008 216(1):83-92. 
26. Rubin D, Hudnall SD, Aisenberg A, Jacobson JO, Harris NL: Richter's transformation of chronic lymphocytic leukemia with Hodgkin's-like cells is associated with Epstein-Barr virus infection. Mod Pathol 1994, 7(1):91-98.

27. Shields DJ, Byrd JC, Abbondanzo SL, Lichy JH, Diehl LF, Aguilera NI: Detection of Epstein-Barr virus in transformations of low-grade B-cell lymphomas after fludarabine treatment. Mod Pathol 1997, 10(11):1151-1159.

28. Pescarmona E, Pignoloni P, Mauro FR, Cerretti R, Anselmo AP, Mandelli F, Baroni CD: Hodgkin/Reed-Sternberg cells and Hodgkin's disease in patients with B-cell chronic lymphocytic leukaemia: an immunohistological, molecular and clinical study of four cases suggesting a heterogeneous pathogenetic background. Virchows Arch 2000, 437(2):129-132

29. Thornton PD, Bellas C, Santon A, Shah G, Pocock C, Wotherspoon AC, Matutes E, Catovsky D: Richter's transformation of chronic lymphocytic leukemia. The possible role of fludarabine and the Epstein-Barr virus in its pathogenesis. Leuk Res 2005, 29(4):389-395.

30. Ren Q, Sato H, Murono S, Furukawa M, Yoshizaki T: Epstein-Barr virus (EBV) latent membrane protein 1 induces interleukin-8 through the nuclear factor-kappa B signaling pathway in EBV-infected nasopharyngeal carcinoma cell line. Laryngoscope 2004, 114(5):855-859.

31. Murono S, Inoue H, Tanabe T, Joab I, Yoshizaki T, Furukawa M, Pagano JS: Induction of cyclooxygenase-2 by Epstein-Barr virus latent membrane protein 1 is involved in vascular endothelial growth factor production in nasopharyngeal carcinoma cells. Proc Natl Acad Sci USA 2001, 98(12):6905-6910.

32. Nakagomi H, Dolcetti R, Bejarano MT, Pisa P, Kiessling R, Masucci MG: The Epstein-Barr virus latent membrane protein-1 (LMP1) induces interleukin-10 production in Burkitt lymphoma lines. Int I Cancer 1994, 57(2):240-244.

33. Fayad L, Keating MJ, Reuben JM, O'Brien S, Lee BN, Lerner S, Kurzrock R: Interleukin-6 and interleukin-10 levels in chronic lymphocytic leukemia: correlation with phenotypic characteristics and outcome. Blood 2001, 97(1):256-263.

34. Dukers DF, Meij P, Vervoort MB, Vos W, Scheper RJ, Meijer CJ, Bloemena E, Middeldorp JM: Direct immunosuppressive effects of EBV-encoded latent membrane protein 1. J Immunol 2000, 165(2):663-670.

doi:10.1186/1750-9378-5-22

Cite this article as: Dolcetti and Carbone: Epstein-Barr virus infection and chronic lymphocytic leukemia: a possible progression factor? Infectious Agents and Cancer 2010 5:22.

\section{Submit your next manuscript to BioMed Central and take full advantage of:}

- Convenient online submission

- Thorough peer review

- No space constraints or color figure charges

- Immediate publication on acceptance

- Inclusion in PubMed, CAS, Scopus and Google Scholar

- Research which is freely available for redistribution

Submit your manuscript at www.biomedcentral.com/submit 